\title{
Examining mathematics teachers' conceptions, practices, and opportunities for change
}

\author{
Gwendolyn M. Lloyd ${ }^{1}$
}

Published online: 9 November 2016

(C) Springer Science+Business Media Dordrecht 2016

The articles in this issue of the Journal of Mathematics Teacher Education report about studies of mathematics teachers' conceptions, the practices that comprise their classroom instruction, and opportunities to enhance conceptions and practices. As a set, the studies examine the conceptions and instruction of prospective elementary teachers, prospective and inservice secondary teachers, and a mathematics teacher educator in contexts that include a professional development program in the USA and university teacher education courses in the USA and Israel. Guided by diverse perspectives, data sources include taskbased interviews, classroom observations, and prospective teachers' written work and reflections. This collection of articles shares novel analytic tools and reports original findings that contribute in important ways to our knowledge base in mathematics teacher education.

Two articles investigate mathematical understandings or conceptions of prospective teachers [PSTs]. Whereas Amanda Jansen and Charles Hohensee examine elementary PSTs' conceptions of partitive division with fractions, Cynthia Oropesa Anhalt and Ricardo Cortez consider secondary PSTs' evolving understandings of mathematical modeling through the implementation of a modeling module in a teacher education course. PSTs in the USA, where these studies took place, may lack prior experience with partitive division with fractions and mathematical modeling. These articles provide valuable insights into PSTs' conceptions and changes in their understandings that may inform teacher educators' design of instruction about partitive division and mathematical modeling.

Jansen and Hohensee, in "Examining and Elaborating Upon the Nature of Elementary Prospective Teachers' Conceptions of Partitive Division with Fractions," examined the conceptions demonstrated by 17 elementary PSTs in task-based interviews about a partitive model of division with fractions. The researchers put forth a framework of productive conceptions of partitive division involving two components: connectedness, which relates

Gwendolyn M. Lloyd

1loyd@psu.edu

1 The Pennsylvania State University, University Park, PA, USA 
to translating between representations and an awareness that partitive division generates a unit rate, and flexibility, which refers to recognizing that division may involve partitioning, iterating, or both. Three interview tasks were carefully designed to offer opportunities for participants to demonstrate both connectedness and flexibility in their conceptions of partitive division. Participants, selected to represent a range of mathematical understandings, were found to demonstrate disconnected conceptions of partitive division. Notably, these disconnected conceptions were demonstrated by PSTs in different ways that the authors illustrate with examples from interview transcripts. Similarly, the researchers offer details about how participants demonstrated rigid conceptions of partitive division in two different ways. Jansen and Hohensee's analysis of interview data produced nuanced descriptions of PSTs' conceptions of a partitive model of division that both teacher educators and researchers will find useful.

Secondary PSTs' understanding of mathematical modeling is the focus of the article, "Developing Understanding of Mathematical Modeling in Secondary Teacher Preparation." In contrast to Jansen and Hohensee who examined PSTs' conceptions at a fixed point in time during a mathematics course sequence, Anhalt and Cortez explored changes in 11 PSTs' conceptions throughout a mathematical modeling module implemented during a secondary mathematics education course. Data sources included pre- and post-questionnaires, PSTs' individual and team written work from the module activities, and instructor field notes from class discussions during the module. The researchers described how PSTs engaged in the modeling cycle as they worked in teams on a particular task and illustrated how the PSTs' work on the task connected with three mathematical practices of the Common Core State Standards (making sense of problems and persevere in solving them, reason abstractly and quantitatively, and attend to precision). The researchers found that participants, who had no prior exposure to mathematical modeling, improved their understanding of modeling in several important ways, including recognizing differences between modeling and problem-solving, over the course of the study. The result that six participants initially confounded "mathematical modeling" with other meanings of the word "model" underscores PSTs" lack of familiarity with mathematical modeling and the potential value of engagement with the modeling cycle in teacher education coursework, as the authors suggest.

Research over the past several decades has demonstrated that significant changes in instructional practice are complex and difficult, even when teachers are offered opportunities to change their mathematical and pedagogical conceptions. The challenge associated with change in mathematics teachers' practices is central to two articles in this issue. Einat Heyd-Metzuyanim, Michal Tabach, and Talli Nachliedi report about the nature of instructor-led classroom discourse, which appeared on the surface to contain elements of "cognitively demanding, conceptually oriented and student-centered" instruction, in a mathematics course for elementary PSTs in Israel. The article by Yasemin Copur-Gencturk and Anna Papakonstantinou examines changes over time in the instructional practices of high school teachers who participated in a sustained professional development program in the USA. Whereas numerous prior studies have illustrated the complexity of changing mathematics instruction, these articles offer deeper insights into instructional change through a novel framework applied to classroom discourse data (Heyd-Metzuyanim, Tabach, and Nachliedi) and use of a multilevel growth modeling approach to analyzing a longitudinal set of direct observational data (Copur-Gencturk and Papakonstantinou).

In "Opportunities for Learning Given to Prospective Mathematics Teachers: Between Ritual and Explorative Instruction," Heyd-Metzuyanim, Tabach, and Nachliedi apply a communicational "commognitive" framework to describe the instruction in a mathematics 
course for prospective elementary teachers in Israel. The authors distinguish between two types of participation in mathematical discourse: ritual participation, in which the goal is to connect with or please others, and explorative participation, in which the goal is to produce mathematical narratives for their own sake. This distinction is important in this study in light of the researchers' interest in how PSTs experience the learning of mathematics in teacher education coursework. Viewing instructor-led discussions as providing opportunities to learn, the researchers analyzed 11 transcribed lessons from an introductory algebra course required for prospective elementary teachers. Participants in the study included 16 PSTs and their "skilled and popular" instructor. Applying the commognitive framework to the mathematical discourse in the lessons, the researchers reported that the instruction appeared to align more closely with ritual participation than explorative participation. They described a "tug-of-war" between ritual and explorative mathematizing, as represented by the instructor engaging the PSTs in discourse that was pedagogical as well as mathematical and minimizing PSTs' opportunities to make errors or take wrong paths. The authors point to the challenge of shifting underlying assumptions, of both teachers and teacher educators, about what it means to do and succeed with mathematics.

With a focus on inservice teachers, Copur-Gencturk and Papakonstantinou report about the impact of a professional development program intended to improve mathematics instruction in the article, "Sustainable Changes in Teacher Practices: A Longitudinal Analysis of the Classroom Practices of High School Mathematics Teachers." Core features of the professional development program included a focus on content and pedagogical content knowledge, provision of active learning experiences for participants, explicit connections to teachers' daily work, and activities sustained over time. The researchers were interested to determine what mathematics teaching practices appeared to change following teachers' participation in the program and which practices seemed most resistant to change. The classroom instruction of 49 teachers from two cohorts and 34 high schools in two school districts were observed over four years, beginning after teachers' participation in their first summer of professional development. The researchers used an observation instrument designed to detect changes expected as a result of the professional development program. They conducted factor analyses to identify the distinct instructional features captured by the observation instrument and used multilevel growth modeling to explore the extent to which practices changed over time. Based on this analysis, CopurGencturk and Papakonstantinou found that teachers made statistically significant, steady changes in several instructional features (mathematical discourse, instructional clarity, and the development of students' mathematical habit of mind), but not in two others (student interactions and the use of multiple representations). Although teachers made improvements in student interactions immediately, teachers did not sustain these practices over the time of the study. In contrast, teachers' use of multiple representations did not change noticeably over the time of the study. Because it examines the impact of a sustained effort to improve instruction and analyzes data from direct measures of classroom instruction over multiple years, this study offers important information as well as new questions about professional development programs and their long-term impact on mathematics teachers' classroom practices. 